Neuroepidemiology 2009;33:358

DOI: $\underline{10.1159 / 000254573}$

\section{Epidemiological Implications of the New Definition of Transient Ischemic Attack}

Yannick Béjot, Maurice Giroud

Stroke Registry of Dijon (Inserm et Institut de Veille Sanitaire), EA4184, University Hospital and Faculty of Medicine and

Department of Neurology, Dijon, France

The new definition of transient ischemic attack (TIA) - i.e. a brief episode of neurologic dysfunction caused by focal brain or retinal ischemia, with clinical symptoms typically lasting less than $1 \mathrm{~h}$, and without evidence of acute infarction - was first suggested in 2002 [1]. This change in the definition was justified by several reasons, including the fact that TIAs should not be considered benign. Indeed, after a first TIA, $2.5-5 \%$ of patients have a stroke within the next $48 \mathrm{~h}$, and $5-10 \%$ within the first month [1-3].

Although this new definition is useful in clinical practice since the management in terms of secondary prevention of patients with either stroke or TIA is similar, it raises methodological questions for epidemiological investigations of stroke. The assessment of the incidence of stroke within a population is mainly based on the exhaustive ascertainment of cases, which requires both a clear definition of what must be measured and validated populationbased registries [4]. Most of the studies from such registries have defined stroke according to the WHO criteria, i.e. rapidly developing clinical signs of focal (at times global) disturbance of cerebral function lasting more than $24 \mathrm{~h}$ or leading to death, with no apparent cause other than that of vascular origin. With the new definition of TIA, a neurological dysfunction lasting less than $24 \mathrm{~h}$ but with proof of infarction on imaging should now be considered as a stroke.

Previous population-based studies have demonstrated that the incidence of TIA, defined according to the classical definition, varies from 11 to 83/100,000/year [5-9]. Nevertheless, the proportion of such TIA patients with cerebral infarction on brain imaging is unknown. This proportion could vary from one study to another, and is considerably influenced by the use of resources, i.e. the proportion of brain MRI performed in patients with transient neurological symptoms, which is highly inconsistent between studied populations. For example, in the stroke registry of Dijon, France, only $15 \%$ of TIA patients had a brain MRI over the study period 2000-2004 [9]. As a consequence, comparing the incidence of stroke from one region to another could be biased according to the proportion of patients with transient neurological symptoms who benefit from a brain MRI, especially since some of them would be classified as stroke patients if an ischemic lesion was found.

Consequently, to avoid such biases and to allow comparisons between studies, it appears to be useful to ascertain all cerebrovascular events in population-based registries that evaluate the incidence of stroke. This challenge is of a great importance as it would provide a clear representation of the burden of the disease.

\section{References}

1 Albers GW, Caplan LR, Easton JD, Fayad PB, Mohr JP, Saver JL, Sherman DG, TIA Working Group: Transient ischemic attack - proposal for a new definition. N Engl J Med 2002;347:1713-1716.

-2 Johnston SC, Gress DR, Browner WS, Sidney S: Short-term prognosis after emergency department diagnosis of TIA. JAMA 2000;284:29012906.

3 Hankey GJ: Redefining risks after TIA and minor ischaemic stroke. Lancet 2005;365:2065-2066.

4 Sudlow CL, Warlow CP: Comparing stroke incidence worldwide: what makes studies comparable? Stroke 1996;27:550-558.

5 Feigin VL, Shishkin SV, Tzirkin GM, Vinogradova TE, Tarasov AV, Vinogradov SP, Nikitin YP: A population-based study of transient ischemic attack incidence in Novosibirsk, Russia, 1987-1988 and 19961997. Stroke 2000;31:9-13

6 Brown RD Jr, Petty GW, O'Fallon WM, Wiebers DO, Whisnant JP: Incidence of transient ischemic attack in Rochester, Minnesota, 19851989. Stroke 1998;29:2109-2113.

-7 Kleindorfer D, Panagos P, Pancioli A, Khoury J, Kissela B, Woo D, Schneider A, Alwell K, Jauch E, Miller R, Moomaw C, Shukla R, Broderick JP: Incidence and short-term prognosis of transient ischemic attack in a population-based study. Stroke 2005;36:720-723.

8 Rothwell PM, Coull AJ, Giles MF, Howard SC, Silver LE, Bull LM, Gutnikov SA, Edwards P, Mant D, Sackley CM, Farmer A, Sandercock PA, Dennis MS, Warlow CP, Bamford JM, Anslow P, Oxford Vascular Study: Change in stroke incidence, mortality, case-fatality, severity, and risk factors in Oxfordshire, UK from 1981 to 2004 (Oxford Vascular Study). Lancet 2004;363:1925-1933.

-9 Bejot Y, Rouaud O, Benatru I, Durier J, Caillier M, Couvreur G, Fromont A, Falvo N, Osseby GV, Cottin Y, Zeller M, Millerot E, Marie C, Moreau $\mathrm{T}$, Giroud M: Trends in the incidence of transient ischemic attacks, premorbid risk factors and the use of preventive treatments in the population of Dijon, France from 1985 to 2004. Cerebrovasc Dis 2007;23:126131

Dr. Yannick Béjot

Dijon Stroke Registry, Department of Neurology

University Hospital, 3 Rue du Faubourg Raines

FR-21000 Dijon (France)

Tel. +33 3802937 53, Fax +33 3802936 72, E-Mail ybejot@yahoo.fr

\section{KARGER}

Fax +41613061234 E-Mail karger@karger.ch www.karger.com
() 2009 S. Karger AG, Basel

$0251-5350 / 09 / 0334-0358 \$ 26.00 / 0$ 